\title{
Nanoscale compositional analysis of wurtzite BAIN thin film using atom probe tomography ${ }^{\circledR}$
}

Cite as: Appl. Phys. Lett. 117, 232103 (2020); doi: 10.1063/5.0027861

Submitted: 31 August 2020 - Accepted: 23 November 2020 . Published Online: 7 December 2020

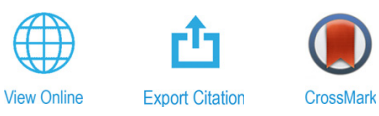

\author{
Jith Sarker, ${ }^{\top}$ Tinh Binh Tran, ${ }^{2}$ \\ and Baishakhi Mazumder, a) \\ Feras AlQatari, ${ }^{2}$ (D) Che-Hao Liao, ${ }^{2}$ (D) Xiaohang Li, ${ }^{2, a)}$ (ID
}

\begin{abstract}
AFFILIATIONS
${ }^{1}$ Department of Materials Design and Innovation, University at Buffalo-SUNY, Buffalo, New York 14260, USA

${ }^{2}$ King Abdullah University of Science and Technology (KAUST), Advanced Semiconductor Laboratory, Thuwal 23955, Saudi Arabia
\end{abstract}

Note: This paper is part of the Special Topic on Ultrawide Bandgap Semiconductors.

a) Authors to whom correspondence should be addressed: baishakh@buffalo.edu and xiaohang.li@kaust.edu.sa

\begin{abstract}
In this work, the local atomic level composition of BAlN films with $\sim 20 \%$ B was investigated using atom probe tomography. Dislocations and elemental clustering were confirmed along which $\mathrm{Al}$ atoms tend to segregate. The presence of local compositional heterogeneities (dislocations and small clusters) and impurities is related to the variation of local alloy stoichiometry of the BAlN films. The roughness and interface abruptness of BAlN/AlN were investigated, and a few $\mathrm{nm}$ of $\mathrm{B}$ and $\mathrm{Al}$ composition gradient in BAlN adjacent to the interface was observed. The nanoscale compositional analysis reported here will be crucial for developing BAlN films with a high B content and larger thickness for future high power electronics and optical applications.
\end{abstract}

Published under license by AIP Publishing. https://doi.org/10.1063/5.0027861

Wurtzite BAlN is a promising ultra-wide bandgap III-nitride alloy with exciting and tunable properties including wide bandgaps in the deep ultraviolet range $(\sim 7 \mathrm{eV}),{ }^{1}$ refractive indices, ${ }^{2}$ band alignment, ${ }^{3-5}$ and a wide range of lattice constants. ${ }^{3,6}$ Due to these attractive properties, BAlN is highly desirable for application in highreflectivity distributed Bragg reflectors (DBRs), vertical cavity surface emitting lasers (VCSELs), barrier layers in power devices, and electron blocking layers (EBLs) in optoelectronics. ${ }^{7-9}$ BAlN layers with a high $B$ content are crucial for achieving a lower refractive index, which enables DBR operation in the DUV regime. 'Despite the tremendous potential of BAlN in future electronics, optics, and photonics, it is extremely challenging to achieve a high B content or high crystallinity wurtzite BAlN films with large thicknesses. ${ }^{10,11}$ The B content in BAlN has been limited by the possible phase separations, the short diffusion length of $\mathrm{B}$, and strong parasitic reactions within the reactor, which may require complex growth methods to address such as flow modulation epitaxy.

A previous study has shown that BAlN with a $12 \%$ B content, grown by metal organic vapor phase epitaxy (MOVPE), had a single phase wurtzite structure that was limited within the first $10 \mathrm{~nm}$ of material. ${ }^{16}$ Beyond this thickness, phase separation was observed resulting from the formation of an undesired tilted-cubic phase due to a lower formation energy of the tilted-cubic phase compared to that of the wurtzite phase. ${ }^{15,16}$ BAlN with an increased B composition (14.4\%) was grown by $\mathrm{MOVPE}^{8}$ that retained the single phase over a larger thickness $(\sim 100 \mathrm{~nm})$. The microstructure of these BAlN films was subjected to screw dislocation defects that significantly deviate the local stoichiometry. Also, lattice parameters used for determining the $\mathrm{B}$ composition in BAlN with varying $\mathrm{B} \%$ were not reliable due to the unavailability of the correct parameters that resulted in an $\sim 2 \%$ error in the reported B content. ${ }^{15}$ Recently, single phase wurtzite BAlN with $>20 \% \mathrm{~B}$ has been reported. ${ }^{17}$ The B content was measured using X-ray diffraction (XRD), secondary neutral mass spectrometry (SNMS), and Rutherford backscattering spectrometry (RBS). While the XRD result suggested a high B content of $\sim 30.9 \%$, the B\% measured by SNMS and RBS was only $\sim 22 \% .{ }^{17}$ The accuracy of the measured composition is usually compromised in XRD due to the lack of knowledge about the exact BAlN lattice constants at B $>20 \%{ }^{15}$ Also, the composition measurement in XRD can be affected by strain and defects in the films. ${ }^{10}$ Any regions in the films not parallel to the substrate would not contribute to the XRD intensity during the $\theta / 2 \theta$ scanning. ${ }^{10}$ Also, the BAIN peaks being much weaker than AlN peaks pose a critical challenge in reciprocal space mapping (RSM) in XRD. ${ }^{15,17}$ On the other hand, the higher sensitivity of RBS to larger atoms than that for smaller atoms like B could present significant uncertainty in the measured composition. ${ }^{10}$ XRD combined with secondary ion mass 
spectroscopy (SIMS) also provided a significant discrepancy in the B composition, which was attributed to the fact that most of the $\mathrm{B}$ formed possible B-related clusters instead of BAlN alloys. ${ }^{11}$ This B segregation was substantiated by the compositional inhomogeneity of $\mathrm{Al}$ and $\mathrm{N}$ observed by scanning transmission electron microscopyelectron diffraction spectroscopy (STEM-EDS). ${ }^{11}$ However, it was not possible to observe the B distribution in STEM-EDS due to the detection limit of the system. Another factor that significantly alters the alloy stoichiometry is the presence of impurities, ${ }^{18}$ which was not well studied in the previous works. Impurities such as $\mathrm{C}, \mathrm{H}$, and $\mathrm{O}$ can be incorporated in BAIN from the trimethylaluminum (TMA), triethylboron (TEB), and ammonia $\left(\mathrm{NH}_{3}\right)$ precursors and $\mathrm{H}_{2}$ carrier gas used during growth. ${ }^{15,17}$ It is crucial to study the effects of these impurities on the local stoichiometry of the BAlN films. Due to these limitations, the $\mathrm{B}$ distribution at the microstructure level remained elusive. To realize the full potential of single-phase wurtzite BAlN at a high B content over a large thickness, it is critical to quantify the B composition in BAlN as well as understanding the evolution of the structural chemistry of the films at the nm scale.

Atom probe tomography (APT) is a nanoscale characterization tool that provides three-dimensional visualization of the composition with a sub-nanometer spatial resolution and $\sim 10$ atomic parts per million sensitivity. ${ }^{19-21}$ For the last few decades, APT has become a potential characterization tool for analyzing wide bandgap materials to provide nanoscale information of many local features such as local compositional homogeneity/inhomogeneity, ${ }^{22-24}$ interfacial roughness, ${ }^{25}$ clustering/segregations, ${ }^{26-29}$ and interfacial adatom diffusion. ${ }^{23,25}$ Such information is significant to explain local chemical and physical properties such as phase transitions, ${ }^{26}$ band offsets, ${ }^{25}$ conductivity, ${ }^{29}$ and doping profile related to the device performance. ${ }^{20}$ In this Letter, the nanoscale compositional analysis of MOCVD-grown BAIN with $\sim 20 \%$ B was investigated using APT. The B content in BAlN films is quantified, and the distribution of $\mathrm{B}$ atoms along the growth in both BAlN films is reported. The effect of impurities on local stoichiometry is explained. The atomic distribution across the BAlN/AlN interfaces was studied. These observations reveal significant information regarding the structural chemistry of BAlN with a high B content over a large thickness, which will aid further development of this material.

The wurtzite BAlN films with $\sim 20 \%$ B were grown on an AlN template on the sapphire substrate by MOCVD. The details of the growth are recently reported elsewhere. ${ }^{17}$ The needle-shaped APT specimens were prepared using an FEI Nova 200 dual-beam focused ion beam (FIB)/scanning electron microscope (SEM) system. The standard lift-out and annular milling techniques were adapted for preparing the sharp APT tips. ${ }^{30}$ The APT data acquisition was performed on a CAMECA LEAP 4000X HR in the laser mode (laser wavelength, $\lambda=355 \mathrm{~nm}$ ). It is reported that the B atoms are subjected to preferential field evaporation, resulting in multi-hit events during APT data acquisition that leads to significant $B$ loss and quantification artifacts. ${ }^{31}$ To quantify the B composition with confidence, we performed APT measurements over a wide range of pulse energies, and the measured B compositions are reported in Table I. It was observed that for a wide range of pulse energies, the $B$ composition did not change significantly that enabled us to confidently quantify the B content in BAIN. At low laser energies (1-10 pJ), the samples were prone to premature failure due to a very high electrostatic field. Additionally, a low signal-to-noise
TABLE I. Laser energy vs obtained B\%.

\begin{tabular}{cc}
\hline \hline Laser energy $(\mathrm{pJ})$ & $\mathrm{B} \%$ \\
\hline $1 \mathrm{pJ}$ & $19.7 \pm 0.1 \%$ \\
$10 \mathrm{pJ}$ & $19.8 \pm 0.1 \%$ \\
$30 \mathrm{pJ}$ & $20.1 \pm 0.1 \%$ \\
$100 \mathrm{pJ}$ & $20.5 \pm 0.2 \%$ \\
$200 \mathrm{pJ}$ & $20.3 \pm 0.2 \%$ \\
\hline \hline
\end{tabular}

ratio (high background) in the mass spectrum was observed. At higher laser energies (100-200 pJ), enhanced thermal tails for B and $\mathrm{Al}$ were observed, indicating thermal migration of these ions prior to their evaporation, which would result in inaccurate composition measurements and inhomogeneous distributions. ${ }^{32}$ Controlled field evaporation for all of the atoms was achieved at an optimized laser energy of $30 \mathrm{pJ}$, a base specimen temperature of $30 \mathrm{~K}$, a $250 \mathrm{kHz}$ pulse repetition rate, and a $0.5 \%$ detection rate. The APT data analysis was conducted using the CAMECA's Integrated Visualization and Analysis Software (IVAS 3.8). The details about APT instrumentation and reconstruction algorithms are reported in the literature. ${ }^{33,34}$

The optimized condition during the experiment enabled efficient acquisition of large datasets ( $>15 \mathrm{M}$ ions) from BAlN films. Figure (a) represents the reconstructed 3D elemental map of BAlN films. Only $\mathrm{N}$ atoms (1\%) are shown for the ease of visualization. The local chemical segregations were represented by 53 at. \% $\mathrm{Al}$ isosurfaces in red. The bulk compositions from BAlN films are measured and reported in Table II. The presence of impurities such as $\mathrm{H}, \mathrm{C}$, and $\mathrm{O}$ within BAlN films was detected and quantified from the time of flight mass spectrum (supplementary material, Figs. S1-S3). There is an ambiguity to accurately quantify the $\mathrm{H}$ content in APT since residual $\mathrm{H}$ in the analysis chamber is usually adsorbed to the specimen between each laser pulsing, which results in an overestimation of $\mathrm{H}^{35}$ The $\mathrm{H}$ measurement provided in Table II is a qualitative assessment for verifying the presence of $\mathrm{H}$ impurity in BAlN rather than an exact $\mathrm{H}$ quantification as it can be affected by the residual $\mathrm{H}$ in the APT analysis chamber. To get rid of a possible $\mathrm{H}$ content overestimation resulting from the residual $\mathrm{H}$ in APT, the bulk $\mathrm{H}$ composition in the AlN template was determined, which would be close to the residual $\mathrm{H}$ concentrations. This $\mathrm{H}$ content in AlN was subtracted from the bulk $\mathrm{H}$ obtained in BAlN to get the approximate $\mathrm{H}$ impurity in the BAlN films. This process was repeated on multiple samples and on the single BAIN thin film and with a BAIN/AlN structure; all of them provided similar results. To report the alloy composition accurately within the BAlN film, the site-III compositions for $\mathrm{B}$ and $\mathrm{Al}$ are reported in Table II to eliminate the quantification artifacts from nitrogen loss, evident in nitride semiconductors. ${ }^{36,37}$ In the BAIN films, the average site-III bulk composition is found to be $20.1 \pm 0.2 \% \mathrm{~B}$ and $79.8 \pm 0.8 \%$ of $\mathrm{Al}$.

The BAIN local stoichiometry and compositional homogeneity can be affected by inhomogeneous chemical distribution such as local segregations/clustering, ${ }^{10}$ nanoscale disordered precipitates, ${ }^{11}$ defect sites (dislocations and twins), ${ }^{10,17}$ or the presence of impurities. ${ }^{38,39}$ To address these issues, we have performed an in-depth analysis of the local composition of the BAlN films. Isosurface analysis (isosurface parameters were described previously) revealed the presence of $\mathrm{Al}$ rich regions as shown in Fig. 1(a). The site-III bulk compositions of the 
(a)

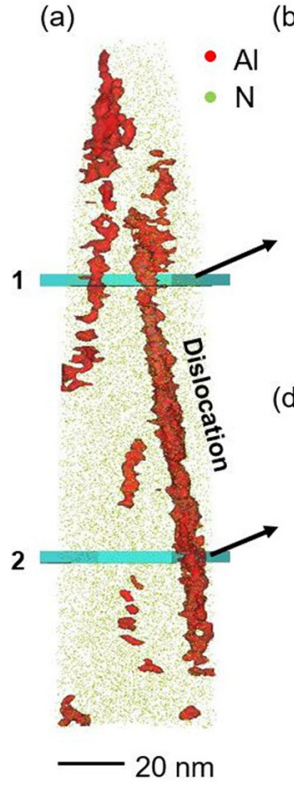

(b)

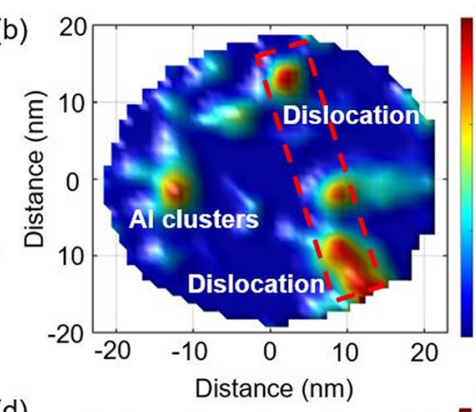

(d)

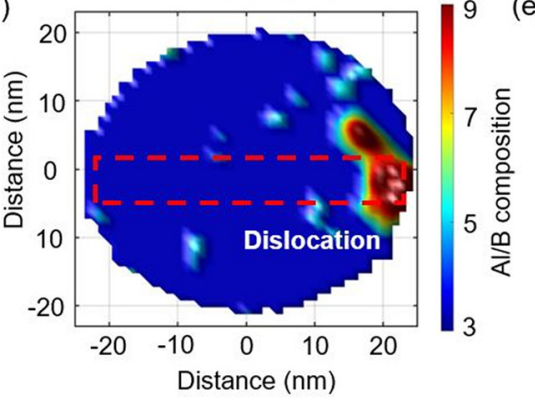

(c)

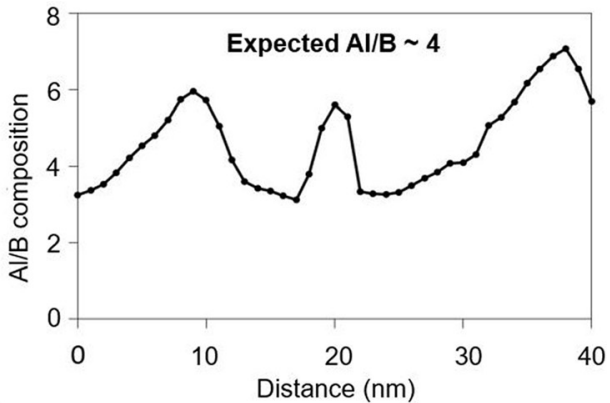

(e)

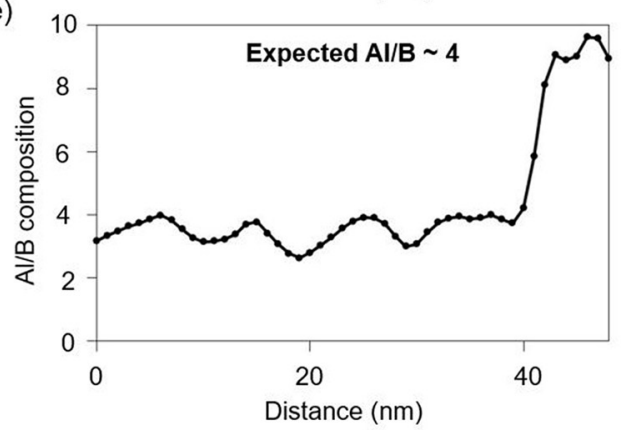

FIG. 1. (a) 3D elemental map of the BAIN layer, showing dislocation and Al-rich clusters at 53 at. \% $\mathrm{Al}$ isosurface, (b) Al/B ratio along the lateral plane within the volume indicated by the black arrow, and (c) Al/B profile along the red dotted region in (b); (d) Al/B distribution along the lateral plane within the volume indicated by the black arrow and (e) Al/B profile along the red dotted region in (d).

major species (B and $\mathrm{Al}$ ) within these segregated regions and in uniform regions with no segregations were measured by extracting $6 \mathrm{~nm} \times 6 \mathrm{~nm} \times 6 \mathrm{~nm}$ volumes from both areas. These segregated regions have site-III bulk compositions of $10.2 \pm 0.03 \% \mathrm{~B}$ and $87.5 \pm 0.08 \% \mathrm{Al}$, while outside these segregations, the site-III compositions were $21.2 \pm 0.04 \% \mathrm{~B}$ and $76.7 \pm 0.1 \% \mathrm{Al}$. These $\mathrm{Al}$ enriched regions extend along with the growth of the BAlN films, implying the presence of dislocations. ${ }^{40}$ The possible reason for $\mathrm{Al}$ segregation along the dislocations could be due to the relatively higher diffusion length of $\mathrm{Al}$ atoms than that of $\mathrm{B}$ atoms. ${ }^{13}$ The variation of local chemical heterogeneity was investigated by plotting the lateral Al/B distributions. Two representative volumes $(50 \mathrm{~nm} \times 50 \mathrm{~nm} \times 4 \mathrm{~nm})$ were extracted from the top and bottom parts of the BAlN film to observe the lateral $\mathrm{Al} / \mathrm{B}$ composition ratio on the XY plane. Figure 1 (b) shows the lateral $\mathrm{Al} / \mathrm{B}$ ratio along the $\mathrm{XY}$ plane for the volume indicated by

TABLE II. The bulk compositions of BAIN films.

\begin{tabular}{lc}
\hline \hline Element & Bulk composition in BAlN with 22\% B \\
\hline $\mathrm{B}$ & $11.8 \pm 0.1 \%$ \\
$\mathrm{Al}$ & $46.9 \pm 0.4 \%$ \\
$\mathrm{~N}$ & $37.9 \pm 0.2 \%$ \\
$\mathrm{C}$ & $0.1 \pm 0.05 \%$ \\
$\mathrm{H}$ & $2.5 \pm 0.1 \%$ \\
$\mathrm{O}$ & $0.3 \pm 0.04 \%$ \\
Site-III B & $20.1 \pm 0.2 \%$ \\
Site-III Al & $79.8 \pm 0.8 \%$ \\
\hline \hline
\end{tabular}

the black arrow. While the expected $\mathrm{Al} / \mathrm{B}$ ratio is $\sim 4$ from the measured $\mathrm{B}$ and $\mathrm{Al}$ compositions in $\mathrm{APT}$, four regions with a high $\mathrm{Al} / \mathrm{B}$ ratio of $\sim 8$ were observed. Two of these regions were identified as the dislocation sites where $\mathrm{Al}$ atoms are segregating. The other high $\mathrm{Al} / \mathrm{B}$ regions were attributed to two small volumes of $\mathrm{Al}$ clusters. The $1 \mathrm{D}$ $\mathrm{Al} / \mathrm{B}$ concentration profile along the red dotted region in Fig. 1(b) is illustrated in Fig. 1(c) to quantify the extent of $\mathrm{Al}$ segregation in the dislocations and in the clustered regions. From Fig. 1(c), an Al/B ratio as high as 6-8 was observed in the dislocation sites and in the Al-rich clusters, while the expected $\mathrm{Al} / \mathrm{B}$ ratio of $\sim 4$ was maintained outside these high density regions. Similar lateral Al/B distribution analysis was performed within a volume taken from the lower regime [shown by the black arrow in Fig. 1(a)] of this film and is shown in Fig. 1(d). The dislocation site was identified by the high $\mathrm{Al}$ density region with a high $\mathrm{Al} / \mathrm{B}$ ratio of $\sim 9$, while outside this region, the $\mathrm{Al} / \mathrm{B}$ ratio closely resembles the expected value. Figure 1 (e) illustrates the $1 \mathrm{D}$ concentration profile for the red dotted region in Fig. 1(d) where this Al segregation in the dislocation site was confirmed with an $\mathrm{Al} / \mathrm{B}$ ratio of $\sim 9$, while outside this $\mathrm{Al}$ segregated zone, an average $\mathrm{Al} / \mathrm{B}$ ratio of $\sim 4$ is observed. Such local variations of the $\mathrm{Al} / \mathrm{B}$ ratio in the studied BAlN films indicate that the film quality needs to be improved through the optimization of growth parameters and techniques. The randomness of the BAlN films away from the dislocations and $\mathrm{Al}$ clustered regions within these representative top and bottom volumes was also investigated and is reported in Fig. S4 of the supplementary material.

The local stoichiometry of the films can also be affected by the presence of impurities such as $\mathrm{H}, \mathrm{C}$, and $\mathrm{O}$, incorporated during the growth that adversely affects the BAlN transmission efficiency. ${ }^{39}$ From Table II, it was found that a high concentration of $\mathrm{H}$ impurities is 
present in the BAlN film. To avoid the ambiguity and assess the $\mathrm{H}$ distribution within the BAlN film, we plotted the depth profile of $\mathrm{H}$ throughout the BAlN films and AlN template. To collect ions through the BAlN/AlN interfaces, the APT acquisitions were repeated with the same experimental conditions for a film with reduced thickness $(\sim 60 \mathrm{~nm})$ to avoid premature fracture of the specimen that was the case for BAlN films with an $\sim 250 \mathrm{~nm}$ thickness. Figure 2(a) shows the $3 \mathrm{D}$ atomic map of the BAlN/AlN structure with a BAlN layer thickness of $\sim 60 \mathrm{~nm}$. Figure 2(b) presents the depth profile of the $\mathrm{B}, \mathrm{Al}$, and $\mathrm{H}$ of the BAlN film on the AlN template. The depth profile clearly reveals that the $\mathrm{H}$ concentration in the BAIN layer is significantly higher than that in the AlN template, confirming the presence of $\mathrm{H}$ as an impurity in BAIN. The change in alloy stoichiometry of the BAIN films was further investigated by observing the lateral variation of local $\mathrm{Al}$ and $\mathrm{B}$ contents with $\mathrm{H}$ impurities. Similar profiles with $\mathrm{C}$ and $\mathrm{O}$ impurities were not possible to achieve because of their low count subjected to a significant noise in their respective concentration profile. Figures 2(c)-2(f) show the concentration profile of $\mathrm{B}$ and $\mathrm{Al}$ with $\mathrm{H}$ in BAlN films for the volume extracted from the top (region 1) and bottom regions (region 2) of the BAlN film shown in Fig. 1(a). The lateral variations of $\mathrm{H}$ compositions in regions 1 and 2 follow the change in $\mathrm{B}$ concentration profiles as shown in Figs. 2(c) and 2(e), respectively. The $\mathrm{H}$ concentration increases as the $\mathrm{B}$ concentration increases and vice versa. In contrast, the $\mathrm{H}$ content in regions 1 and 2 varies inversely with $\mathrm{Al}$ as shown in Figs. 2(d) and 2(f), respectively. The $\mathrm{H}$ impurity atoms incorporated in BAlN during the growth would occupy in interstitial sites. The in-phase relation of the $\mathrm{H}$ profile with $\mathrm{B}$ and antiphase variation of $\mathrm{H}$ with the $\mathrm{Al}$ concentration could be an indication that $\mathrm{H}$ atoms are located to interstitial positions much closer to $\mathrm{B}$ and away from $\mathrm{Al}$ atoms. ${ }^{41}$ This variation of the $\mathrm{H}$ profile with $\mathrm{B}$ and $\mathrm{Al}$ contents was confirmed by repeating this analysis in different regions of the BAlN films and is presented in Fig. S5 of the supplementary material. This significant amount of $\mathrm{H}$ impurities would move the $\mathrm{Al}$ atoms by forming $\mathrm{Al}-\mathrm{H}$ bonds and would affect the microstructure of the BAlN films since these $\mathrm{Al}-\mathrm{H}$ bonds are $\sim 5 \%$ shorter than $\mathrm{Al}-\mathrm{N}$ bonds. ${ }^{41}$ This structural deviation may drastically affect the refractive index property of BAlN. ${ }^{42}$ Also, the presence of $\mathrm{H}$ impurities would prevail the conductivity of the BAlN films by compensating charge carriers. $^{41}$

Figure 3 illustrates the interface profile of the BAlN/AlN structure. The 3D atomic map of the BAIN/AlN structure used in Fig. 2(a) is shown with only $\mathrm{B}$ and $\mathrm{N}$ atoms in dark green and light green is presented in Fig. 3(a). The corresponding 1D concentration profile along the growth direction is shown in Fig. 3(b). The average B concentration in BAlN was $~ 20 \%$; however, from the $1 \mathrm{D}$ profile in Fig. 3(b), a few $\mathrm{nm}$ compositional gradient of $\mathrm{B}$ and $\mathrm{Al}$ was observed across the interface. The interfacial abruptness (compositional grading) was determined from the distance over which the average $\mathrm{B}$ composition varies from 10 to $90 \%{ }^{43}$ and was $\sim 1.5 \mathrm{~nm}$. The interface root mean square roughness was measured by using 6 at. \% B isosurfaces to be $\sim 0.5 \mathrm{~nm}$. This interface roughness is also an indication that the interface abruptness is affected by the composition gradient, possibly due to very minor inter-diffusion of $\mathrm{B}$ and $\mathrm{Al}$ atoms at the BAlN/AlN interface.

An in-depth nano-compositional analysis of BAlN with 20\% B was investigated using APT. It was observed that $\mathrm{Al}$ atoms mainly segregate along defects sites such as dislocations and found to form clusters. A possible reason for this deviation in local stoichiometry could be attributed to the short diffusion length of $\mathrm{B}$ compared to that of $\mathrm{Al}$. The effects of $\mathrm{H}$ impurities on the local alloy stoichiometry were (a)

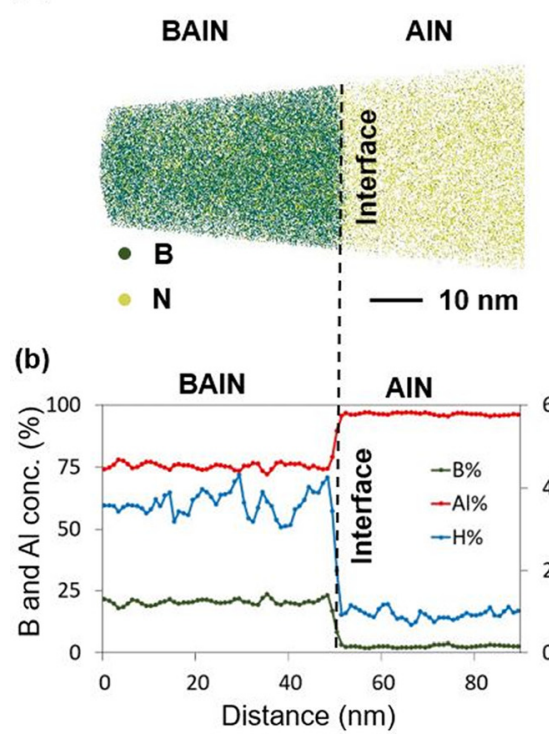

(c)

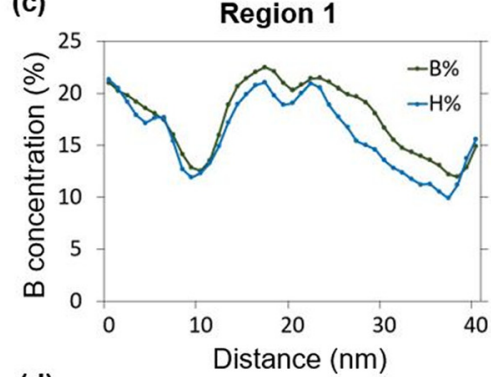

(d)

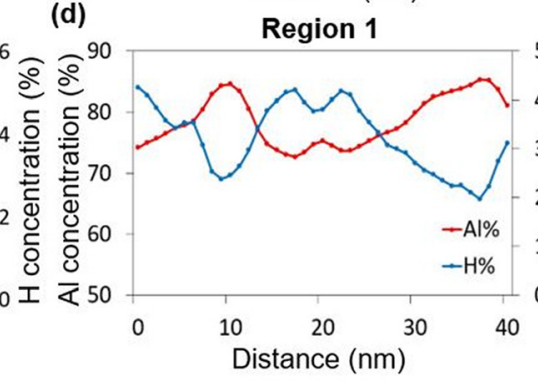

(e)

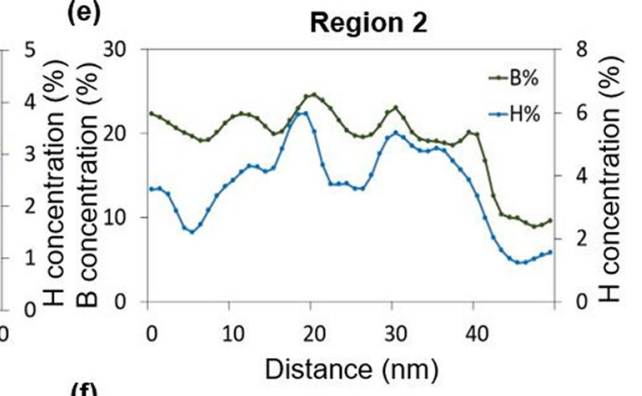

(f)

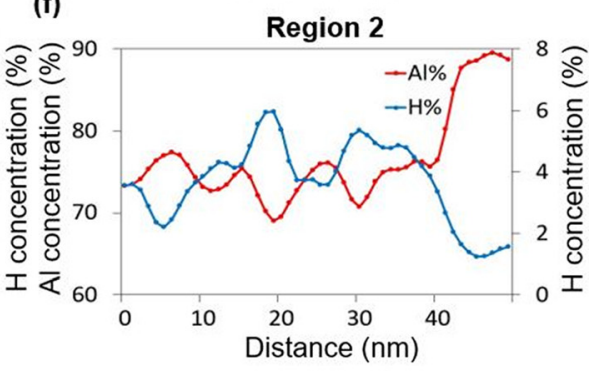

FIG. 2. (a) 3D atomic map of BAIN/AIN; (b) depth profile of $A l, B$, and $H$ (includes residual $H$ from the analysis chamber and $H$ impurities) along the structure shown in (a); (c) lateral $\mathrm{B}$ and $\mathrm{H}$ (residual $\mathrm{H}+\mathrm{H}$ impurity atoms) profile in region 1 marked in Fig. 1(a); (d) lateral $\mathrm{Al}$ and $\mathrm{H}$ (residual $\mathrm{H}+\mathrm{H}$ impurity atoms) profile in region 1 marked in Fig. 1(a); (d) lateral $\mathrm{B}$ and $\mathrm{H}$ (residual $\mathrm{H}+\mathrm{H}$ impurity atoms) profile in region 2 marked in Figs. 1(a); and (e) lateral $\mathrm{Al}$ and $\mathrm{H}$ (residual $\mathrm{H}+\mathrm{H}$ impurity atoms) profile in region 2 marked in Fig. 1(a). 
(a) Cross sectional view

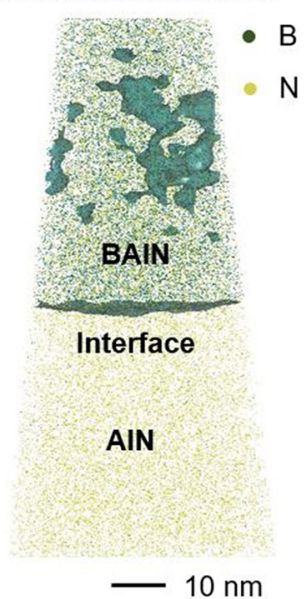

(b) Planar view

(c)

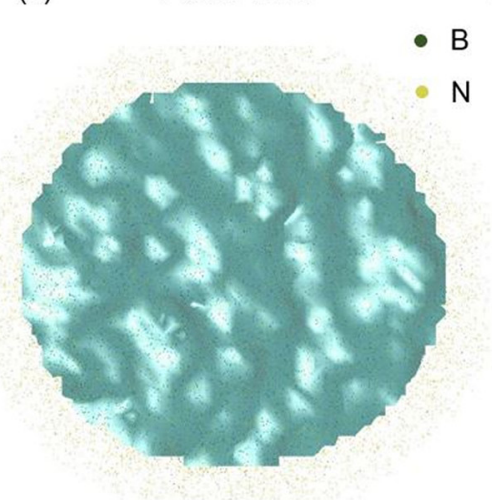

Interface rms roughness $0.5 \mathrm{~nm}$

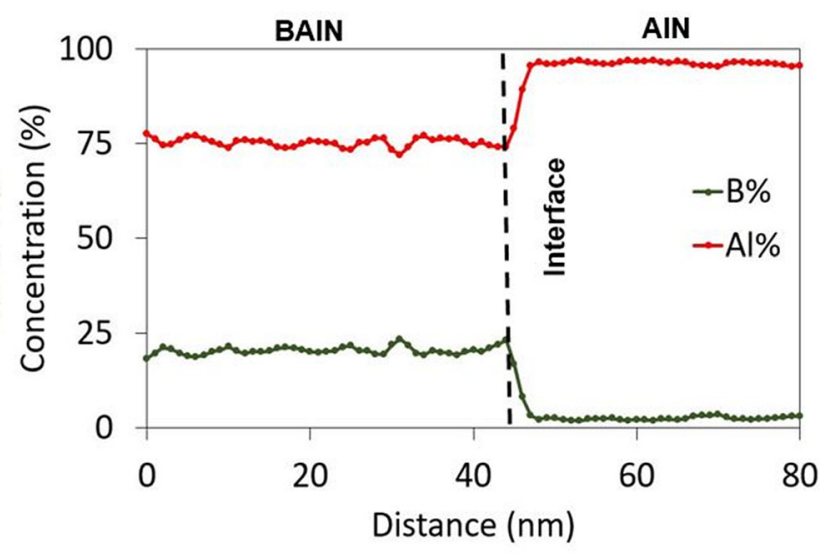

FIG. 3. (a) Analyzed volume to capture the BAIN/AIN interface with 5.9 at. \% B isosurface (cross-sectional view), (b) planar view of BAIN/AIN interface, and (c) proximity histogram profile showing $B$ and $A l$ concentrations across the interface.

investigated. The possible substitution of III-site $\mathrm{Al}$ by $\mathrm{H}$ impurities could be responsible for local stoichiometric deviation; further analysis with the tuning growth condition is needed. The BAlN/AlN interface exhibited a few $\mathrm{nm}$ gradient change in the $\mathrm{B}$ and $\mathrm{Al}$ composition. Further investigation is needed to understand this composition gradient at the interface. The significant structural and compositional information regarding BAlN at a higher B content would be important in developing high quality material for future power electronics and optics.

See the supplementary material for the film's randomness away from dislocations and $\mathrm{H}$ distribution with $\mathrm{B}$ and $\mathrm{Al}$.

APT experiments were conducted at ORNL's Center for Nanophase Materials Sciences (CNMS), which is a U.S. DOE Office of Science User Facility. The authors would like to thank Jonathan Poplawsky and James Burns for performing sample preparation and running the APT experiments. The KAUST authors appreciate the support of KAUST Baseline Fund BAS/1/1664-01-01, Competitive Research Grant Nos. URF/1/3437-01-01 and URF/1/ 3771-01-01, and GCC Research Council No. REP/1/3189-01-01.

\section{DATA AVAILABILITY}

The data that support the findings of this study are available within the article.

\section{REFERENCES}

${ }^{1}$ C.-H. Liao, F. AlQatari, and X. Li, "Band structures and direct-to-indirect bandgap transitions in BAlN and BGaN alloys: A first principle study," arXiv:2005.08274 (2020)

${ }^{2}$ F. Alqatari, M. Sajjad, R. Lin, K. Li, U. Schwingenschlogl, and X. J. A M. S. Li, "Optical properties of BalN and BGaN for applications in latticematched UV optical structures,” arXiv:1803.10011 (2020).

${ }^{3}$ H. Sun, Y. J. Park, K.-H. Li, X. Liu, T. Detchprohm, X. Zhang, R. D. Dupuis, and X. Li, Appl. Surf. Sci. 458, 949 (2018).

${ }^{4}$ H. Sun, Y. J. Park, K.-H. Li, C. G. T. Castanedo, A. Alowayed, T. Detchprohm, R. D. Dupuis, and X. Li, Appl. Phys. Lett. 111, 122106 (2017).
${ }^{5}$ A. A. Sulami, F. Alqatari, and X. Li, "Band alignments of emerging wurtzite BAlN and BGaN semiconductors,” arXiv:2005.08407v1 (2020).

${ }^{6}$ K. Liu, H. Sun, F. AlQatari, W. Guo, X. Liu, J. Li, C. G. T. Castanedo, and X. Li, Appl. Phys. Lett. 111, 222106 (2017).

${ }^{7}$ L. Rongyu, L. Xinwei, L. Kaikai, L. Yi, L. Xinke, and L. Xiaohang, J. Phys. D: Appl. Phys. 53, 48LT01 (2020).

${ }^{8}$ H. Sun, F. Wu, Y. J. Park, T. M. A. tahtamouni, C.-H. Liao, W. Guo, N. Alfaraj, K.-H. Li, D. H. Anjum, T. Detchprohm, R. D. Dupuis, and X. Li, Appl. Phys. Express 11, 011001 (2018).

${ }^{9}$ M. Abid, T. Moudakir, G. Orsal, S. Gautier, A. En Naciri, Z. Djebbour, J.-H. Ryou, G. Patriarche, L. Largeau, H. J. Kim, Z. Lochner, K. Pantzas, D. Alamarguy, F. Jomard, R. D. Dupuis, J.-P. Salvestrini, P. L. Voss, and A. Ougazzaden, Appl. Phys. Lett. 100, 051101 (2012).

${ }^{10}$ S. Wang, X. Li, A. M. Fischer, T. Detchprohm, R. D. Dupuis, and F. A. Ponce, J. Cryst. Growth 475, 334 (2017).

${ }^{11}$ M. Imura, Y. Ota, R. G. Banal, M. Liao, Y. Nakayama, M. Takeguchi, and Y. Koide, Phys. Status Solidi A 215, 1800282 (2018).

${ }^{12}$ J. H. Edgar, D. T. Smith, C. R. Eddy, Jr., C. A. Carosella, and B. D. Sartwell, Thin Solid Films 298, 33 (1997).

${ }^{13}$ T. Akasaka, Y. Kobayashi, and T. Makimoto, Appl. Phys. Lett. 91, 041914 (2007).

${ }^{14}$ T. Akasaka and T. Makimoto, Appl. Phys. Lett. 88, 041902 (2006).

${ }^{15}$ X. Li, S. Wang, H. Liu, F. A. Ponce, T. Detchprohm, and R. D. Dupuis, Basic Solid State Phys. 254(8), 1600699 (2017).

${ }^{16}$ X. Li, S. Sundaram, Y. E. Gmili, T. Moudakir, F. Genty, S. Bouchoule, G. Patriarche, R. D. Dupuis, P. L. Voss, J.-P. Salvestrini, and A. Ougazzaden, Phys. Status Solidi A 212(4), 745 (2015).

${ }^{17}$ T. B. Tran, C.-H. Liao, F. AlQatari, and X. Li, Appl. Phys. Lett. 117, 082102 (2020).

${ }^{18}$ A. Köthe, W. Löser, A. Güth, G. Vaerst, and K. Mai, J. Phys., Colloq. 5(C7), C7-C111 (1995).

${ }^{19}$ D. J. Larson, T. Prosa, R. M. Ulfig, B. P. Geiser, and T. F. Kelly, Local Electrode Atom Probe Tomography (Springer Science, US, 2013).

${ }^{20}$ M. A. Khan, S. P. Ringer, and R. Zheng, Adv. Mater. Interfaces 3(12), 1500713 (2016).

${ }^{21}$ T. F. Kelly and M. K. Miller, Rev. Sci. Instrum. 78, 031101 (2007).

${ }^{22}$ O. G. Licata and B. Mazumder, Int. J. High Speed Electron. Syst. 28, 1940005 (2019).

${ }^{23}$ J. Sarker, Y. Zhang, M. Zhu, S. Rajan, J. Hwang, and B. Mazumder, Microsc. Microanal. 25(Suppl. 2), 2508 (2019).

${ }^{24}$ B. Mazumder, J. Sarker, Y. Zhang, J. M. Johnson, M. Zhu, S. Rajan, and J. Hwang, Appl. Phys. Lett. 115, 132105 (2019). 
${ }^{25}$ A. Vaidya, J. Sarker, Y. Zhang, L. Lubecki, J. Wallace, J. D. Poplawsky, K. Sasaki, A. Kuramata, A. Goyal, J. A. Gardella, B. Mazumder, and U. Singisetti, J. Appl. Phys. 126, 095702 (2019).

${ }^{26}$ J. Sarker, S. Broderick, A. F. M. A. U. Bhuiyan, Z. Feng, H. Zhao, and B. Mazumder, Appl. Phys. Lett. 116, 152101 (2020).

${ }^{27}$ A. F. M. A. U. Bhuiyan, Z. Feng, J. M. Johnson, H.-L. Huang, J. Sarker, M. Zhu, M. R. Karim, B. Mazumder, J. Hwang, and H. Zhao, APL Mater. 8, 031104 (2020).

${ }^{28}$ J. E. Schmidt, L. Peng, A. L. Paioni, H. L. Ehren, W. Guo, B. Mazumder, D. A. M. de Winter, Ö. Attila, D. Fu, A. D. Chowdhury, K. Houben, M. Baldus, J. D. Poplawsky, and B. M. Weckhuysen, J. Am. Chem. Soc. 140, 9154 (2018).

${ }^{29}$ E. Rocco, O. Licata, I. Mahaboob, K. Hogan, S. Tozier, V. Meyers, B. McEwen, S. Novak, B. Mazumder, M. Reshchikov, L. D. Bell, and F. ShahedipourSandvik, Sci. Rep. 10, 1426 (2020).

${ }^{30} \mathrm{~K}$. Thompson, D. Lawrence, D. J. Larson, J. D. Olson, T. F. Kelly, and B. Gorman, Ultramicroscopy 107, 131 (2007).

${ }^{31}$ F. Meisenkothen, E. B. Steel, T. J. Prosa, K. T. Henry, and R. P. Kolli, Ultramicroscopy 159, 101 (2015).

${ }^{32}$ Y. Tu, H. Takamizawa, B. Han, Y. Shimizu, K. Inoue, T. Toyama, F. Yano, A. Nishida, and Y. Nagai, Ultramicroscopy 173, 58 (2017).
${ }^{33}$ B. Gault, D. Haley, F. de Geuser, M. P. Moody, E. A. Marquis, D. J. Larson, and B. P. Geiser, Ultramicroscopy 111, 448 (2011).

${ }^{34}$ P. Bas, A. Bostel, B. Deconihout, and D. Blavette, Appl. Surf. Sci. 87-88, 298 (1995).

${ }^{35}$ R. P. Kolli, Adv. Struct. Chem. Imaging 3, 10 (2017).

${ }^{36}$ B. Mazumder, S. W. Kaun, J. Lu, S. Keller, U. K. Mishra, and J. S. Speck, Appl. Phys. Lett. 102, 111603 (2013).

${ }^{37}$ S. W. Kaun, B. Mazumder, M. N. Fireman, E. C. H. Kyle, U. K. Mishra, and J. S. Speck, Semicond. Sci. Technol. 30, 055010 (2015).

${ }^{38}$ T. Sakai and M. Iwata, J. Mater. Sci. 12, 1659 (1977).

${ }^{39}$ X. Li, S. Sundaram, Y. ElGmili, F. Genty, S. Bouchoule, G. Patriache, P. Disseix, F. Réveret, J. Leymarie, J.-P. Salvestrini, R. D. Dupuis, P. L. Voss, and A. Ougazzaden, J. Cryst. Growth 414, 119 (2015).

${ }^{40}$ M. K. Miller, Microsc. Res. Tech. 69, 359 (2006).

${ }^{41}$ S. Limpijumnong and C. G. Van de Walle, Phys. Status Solidi B 228(1), 303 (2001).

${ }^{42}$ M. Bosund, T. Sajavaara, M. Laitinen, T. Huhtio, M. Putkonen, V.-M. Airaksinen, and H. Lipsanen, Appl. Surf. Sci. 257, 7827 (2011).

${ }^{43}$ B. Mazumder, M. H. Wong, C. A. Hurni, J. Y. Zhang, U. K. Mishra, and J. S. Speck, Appl. Phys. Lett. 101, 091601 (2012). 